\title{
OriginaL
}

\section{Delay in the onset of puberty of intrauterine growth retarded female rats cannot be rescued with hypernutrition after birth}

\author{
Ganbat Gereltsetseg, Toshiya Matsuzaki, Takeshi Iwasa, Riyo Kinouchi, Hiroshi Nakazawa, \\ Satoshi Yamamoto, Akira Kuwahara, Toshiyuki Yasui and Minoru Irahara
}

Department of Obstetrics and Gynecology, Institute of Health Biosciences, The University of Tokushima Graduate School, Tokushima 770-8503, Japan

\begin{abstract}
Perinatal undernutrition is known to disturb reproductive development, in particular by delaying the onset of puberty in certain species. Using a rat model, we studied whether hypernutrition after birth can rescue the delayed onset of puberty in intrauterine undernourished female rats. Pregnant rats were divided into two groups: the maternal normal nutrition $(\mathrm{mNN}, \mathrm{n}=8)$ and maternal undernutrition $(\mathrm{mUN}, \mathrm{n}=9)$ groups. In the $\mathrm{mUN}$ group, dams received $50 \%$ of the daily food intake of the mNN group from day 15 of pregnancy until delivery. Pups from both the mNN and mUN dams were then separated into two groups, based on their postnatal feeding conditions: control-normal nutrition (control-NN), control-hypernutrition (control-HN), Intrauterine growth retardation (IUGR)-normal nutrition (IUGR-NN), and IUGRhypernutrition (IUGR-HN). Litter sizes of the hypernutrition groups were controlled to five pups per dam, and normal nutrition groups to 12-13 pups per dam. From postnatal day 30, pups were inspected daily for vaginal opening (VO). The age of VO in the IUGR-NN group was $35.7 \pm 2.4$ days (mean \pm SD), which was significantly delayed compared to that of the control-NN group ( $33.8 \pm 0.8$ days). The age of VO in the IUGR-HN group was $35.5 \pm 2.3$ days, which was significantly delayed compared to that of the control-HN group ( $33.5 \pm 0.8$ days). Interestingly, the age of VO did not differ between the IUGR-NN and IUGR-HN groups. In conclusion, maternal undernutrition delays puberty in female offspring, and this delay in puberty cannot be rescued with hypernutrition after birth.
\end{abstract}

Key words: Intrauterine growth retardation (IUGR), Vaginal opening, Kisspeptin, Leptin

LOW BIRTH WEIGHT resulting from intrauterine growth retardation (IUGR) is associated with increased risk of developing impaired glucose tolerance, type 2 diabetes, hypertension and cardiovascular disease later in adult life [1-3]. During growth retardation, the fetus adapts to the intrauterine environment and survives by altering its metabolic and endocrine set points [4]. The programming of the endocrine axes occurs during critical phases of fetal and early neonatal development, and altered endocrine set points may induce diseases later in life [5]. This concept is referred to as 'fetal programming' or 'developmental origins of health and disease.'

Perinatal undernutrition has been shown to disturb

Submitted Jan. 2, 2012; Accepted Jun. 16, 2012 as EJ11-0392

Released online in J-STAGE as advance publication Jul. 26, 2012

Correspondence to: Toshiya Matsuzaki, Department of Obstetrics and Gynecology, Institute of Health Biosciences, The University of Tokushima Graduate School, 3-18-15, Kuramoto-cho, Tokushima 770-8503, Japan. E-mail: mat@clin.med.tokushima-u.ac.jp reproductive development in the offspring of both rats and sheep. The age of vaginal opening (VO) and the first estrous was delayed, ovarian and testicular growth were drastically retarded and ovulation rate was lower in the undernourished during prenatal period by several kind of animal models in uterine artery ligation, prenatal food or protein restriction and subjected to glucocorticoid overexposure [6-10]. These reports suggest that there is an association between restricted fetal growth and the programming of disease after birth [11-13]. Moreover, these findings extend to humans, as it has been previously suggested that girls with IUGR or low birth weight have an increased risk of anovulation [14, 15].

Postnatal nutrition also plays an important role with respect to developing obesity and affecting reproductive function. For example, IUGR rats overfed during the neonatal period demonstrate catch-up growth and develop obesity in adulthood [16]. Furthermore, since the $19^{\text {th }}$ century, humans from industrial nations have 
demonstrated a markedly lower age of menarche, which is likely related to the substantial improvements made in nutrition, sanitation, and general health [17]. Thus, peripubertal exposure to an unbalanced diet could also affect the prevalence of obesity, leading to the speculation that both increasing adiposity and earlier pubertal development in girls may be directly related [18, 19]. Leptin, an adipose tissue-derived hormone, is a strong candidate for the potential link between nutritional status and the hypothalamic-pituitary-gonadal axis, especially with respect to puberty onset in female rats and mice [20-23]. Interestingly, in humans, obese girls demonstrate earlier onset of puberty and higher serum levels of leptin than lean girls [24, 25].

Kisspeptin is encoded by the Kiss 1 gene, expressed in the hypothalamus, and is known to greatly stimulate gonadotropin-releasing hormone $(\mathrm{GnRH})$ secretion [26-29]. Recently, several studies have suggested that leptin is a putative regulator of hypothalamic kisspeptin expression. Overfeeding of postnatal female rats resulted an increased body weight and vaginal opening in earlier age, together with higher levels of leptin and hypothalamic Kiss 1 mRNA [30]. Hypothalamic Kiss 1 mRNA levels were found to be decreased in leptin deficient $(o b / o b)$ mice and diabetic rats; however, they were augmented with leptin replacement $[31,32]$. In our previous study, decreased hypothalamic kisspeptin activity contributed the delayed onset of puberty in prenatally undernourished female rats [33].

While adequate nutrition is a key permissive factor in pubertal development, it remains unclear whether the onset of puberty in IUGR rats is accelerated by overnutrition leading to excessive adiposity after birth. The purpose of the present study was to determine whether hypernutrition during the neonatal period increases serum leptin levels and rescues the delayed onset of puberty seen in intrauterine undernourished female rats.

\section{Materials and Methods}

\section{Animals}

Pregnant Sprague-Dawley rats were purchased (Charles River Japan, Inc., Tokyo, Japan) and housed individually. Animal rooms were maintained under controlled lighting (14-h light, 10 -h dark cycle) and temperature $\left(24^{\circ} \mathrm{C}\right)$. All animal experiments were conducted in accordance with the ethical standards of the Institutional Animal Care and Use Committee of the University of Tokushima.

\section{Study design}

A total of 17 pregnant rats and their offspring were used in the study (Fig. 1). Pregnant rats were divided into two groups: i) the normal nutrition $(\mathrm{mNN})$ group (n $=8$ ), in which dams were allowed water and standard rat chow ad libitum during the gestation and lactation periods; and ii) the undernutrition $(\mathrm{mUN})$ group $(\mathrm{n}=$ 9), in which dams received $50 \%$ of the daily food intake of the $\mathrm{mNN}$ group from embryonic day 15 until delivery. Maternal body weight changes in both groups were recorded throughout pregnancy. Litter size was determined on postpartum day 1 . Pups from both groups were randomly separated into two groups, according to postnatal feeding conditions: control-normal nutrition (control-NN), control-hypernutrition (control-HN), IUGRnormal nutrition (IUGR-NN), and IUGR-hypernutrition (IUGR-HN). The litter size of the hypernutrition groups was controlled to five pups per dam (this model results in increased weight gain during the suckling period due to higher milk availability to each pup) and the litter size of the normal nutrition groups was controlled to 12-13 pups per dam. All of the pups used in the experiment were reared by randomly selected $\mathrm{mNN}$ dams. Both male and female offspring were used in the experiment prior to weaning, and only female offspring were used in the experiments after weaning. Extra pups and dams from the mUN group were used for another experiment. The animals used for each experiment were randomly chosen from different litters to obviate any litter differences. Pups were weighed at various postnatal ages and weaned at 21 days of age, when the pups of each litter size were housed in groups of three rats per cage, with free access to standard rat chow and tap water. Eight pups were randomly selected from each of the four groups for Experiment 1 conducted on day 28. Residual pups were used for Experiment 2.

Experiment 1. Ovarian and uterine weights, serum hormone levels, and $\mathrm{mRNA}$ expression of hypothalamic parameters on day 28

During the peripubertal period (i.e. postnatal day 28), eight pups from each group were rapidly weighed and decapitated between 09:00 $\mathrm{h}$ and 11:00 $\mathrm{h}$. The ovaries and uterus were dissected and weighed. Trunk blood and the hypothalamic explant were obtained for the measurement of serum luteinizing hormone (LH), follicle stimulating hormone (FSH), and leptin levels, as well as mRNA expression levels of hypothalamic factors, including Kiss 1, Kiss1r (kisspeptin receptor), and GnRH. 


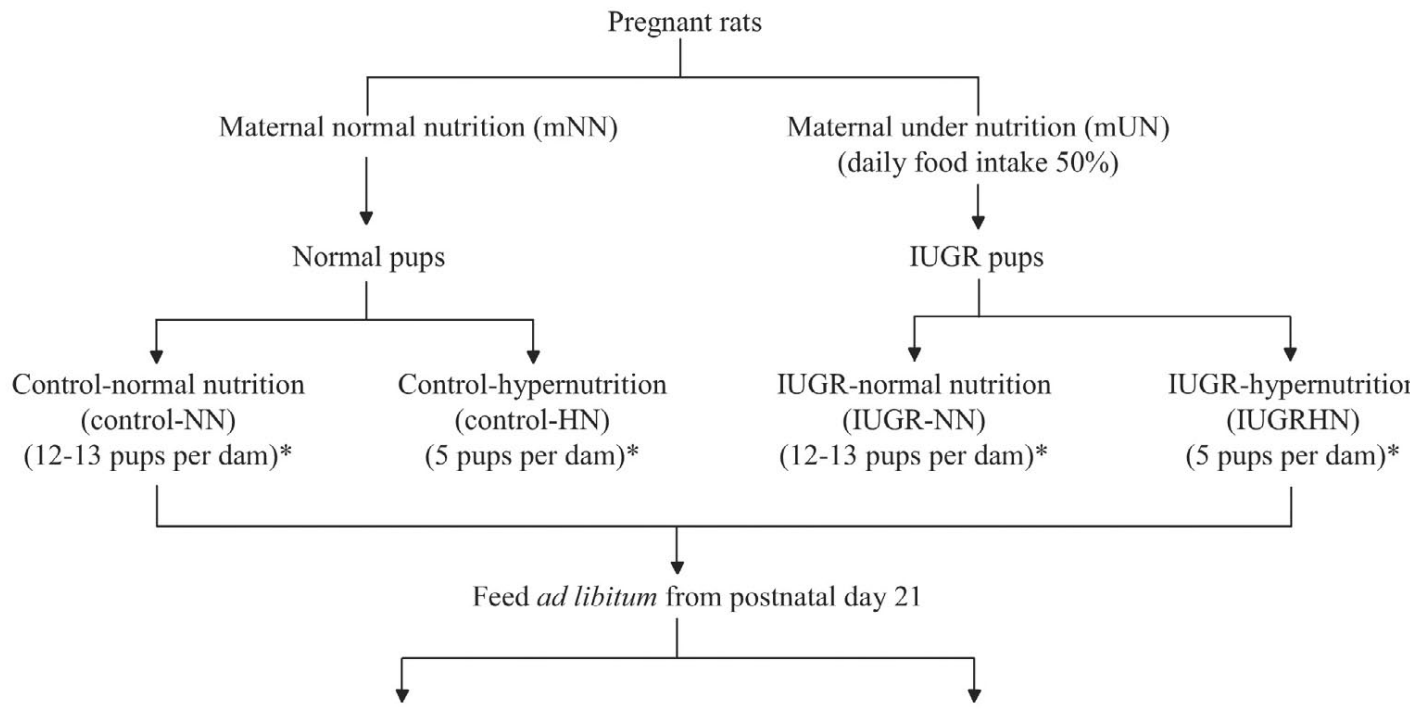

Experiment 1.

On postnatal day 28 , body, ovarian and uterine weights, as well as serum hormone concentrations (i.c., LH, FSH and leptin), and mRNA expression levels of hypothalamic parameters (i.e., Kiss 1, Kiss1r, and GnRH) were determined.

\section{Experiment 2.}

Pups were inspected daily for vaginal opening (VO) from postnatal day 30 .

Fig. 1 Study design

Seventeen pregnant rats were divided into either the maternal normal nutrition (mNN) or maternal undernutrition (mUN) group. Pups from the $\mathrm{mNN}$ and mUN groups were then randomly separated into two groups, according to their postnatal feeding condition: control-NN, control-HN, IUGR-NN, and IUGR-HN. The litter size of the hypernutrition (-HH) groups was controlled to five pups per dam, and the litter size of the normal nutrition groups was controlled to 12-13 pups per dam. Pups were weaned at 21 days of age, and on postnatal day 28, eight pups from each group were randomly selected for Experiment 1 . The residual pups were used in Experiment 2. * all pups were reared by dams originating from the mNN group.

\section{Experiment 2. Age of vaginal opening}

From postnatal day 30, pups were inspected daily for VO. The age of VO, as well as the body weight on the day of $\mathrm{VO}$, were compared between groups.

\section{Hormone assays}

Serum leptin levels were measured using an ${ }^{125} \mathrm{I}-$ radioimmunoassay (RIA) kit (Rat leptin RIA kit, Linco Research Inc., St Charles, MO, USA). The sensitivity of the assay was $0.5 \mathrm{ng} / \mathrm{mL}$. The inter- and intra-assay coefficients of variation (CV) were $4.8 \%$ and $2.4 \%$, respectively. Serum LH levels were measured using an ${ }^{125}$ I-RIA kit (Rat LH [I-125] RIA Kit, Institute of Isotopes Co., Ltd., Tokyo, Japan). The sensitivity of the assay was $0.2 \mathrm{ng} / \mathrm{mL}$. The inter- and intra-assay coefficients of variation $(\mathrm{CV})$ were $6.6 \%$ and $6.5 \%$, respectively. Serum FSH levels were measured using an ${ }^{125}$ I-RIA kit (Rat FSH [I-125] RIA kit, Institute of Isotopes Co., Ltd., Tokyo, Japan). The sensitivity of the assay was $0.09 \mathrm{ng} / \mathrm{mL}$. The inter- and intra-assay coefficients of variation (CV) were $8.1 \%$ and $4.2 \%$, respectively.

\section{Quantitative real time polymerase chain reaction of the rat hypothalamic explants}

Hypothalamic explants, including the median preoptic area, anteroventral periventricular nucleus, and arcuate nucleus, were dissected. Briefly, brain sections were dissected via coronal cuts $1 \mathrm{~mm}$ anterior from the optic chiasm and the posterior border of the mammillary bodies. The sections were cut $2 \mathrm{~mm}$ from the bottom of the hypothalamus, and then trimmed along the hypothalamus sulci.

Total RNA was isolated from the hypothalamus using a TRIzol reagent Kit (Invitrogen Co., Carlsbad, CA, USA) and an RNeasy Mini kit (Qiagen Gmgh, Hilden, Germany). cDNA was synthesized with oligo (deoxythymidine) primers at $50^{\circ} \mathrm{C}$ using the SuperScript III First-Standard Synthesis System for RT-PCR (Invitrogen Co.). Real-time PCR analysis was per- 
formed using the PCR system StepOnePlus (Applied Biosystems, Foster City, CA, USA) with SYBR green Fast (Applied Biosystems). The forward and reverse primers were, as follows: Kiss 1: F: 5'-AGC TGC TGC TGC TTC TTC TCT GT-3' R: 5'-AGG CTT GCT CTC TGC ATA CC-3'; Kiss 1r, F: 5'-GCA GAC CGT CAC CAA TTT CT-3', R: 5'-GGGAAC ACA GTC ACG TAC CA-3'; GnRH: F: 5'- GCA GAA CCC CAG AAC TTG GA-3', R: 5'-TGC CCA GCT TCC TCT TCA AT-3'; and $\beta$-actin: F: 5'-TCA TGA AGT GTG ACG TTG ACA TCC GT-3', R: 5'-CTT AGA AGC ATT TGG GGT GCA CG-3'. The PCR cycling conditions were, as follows: initial denaturation and enzyme activation at $95^{\circ} \mathrm{C}$ for $10 \mathrm{~min}$, followed by 45 cycles of denaturation at $95^{\circ} \mathrm{C}$ for $15 \mathrm{~s}$; annealing at $63^{\circ} \mathrm{C}$ for $30 \mathrm{~s}$ (Kiss-1, Kiss 1 r), $58^{\circ} \mathrm{C}$ for $30 \mathrm{~s}(G n R H)$, and $65^{\circ} \mathrm{C}$ for $30 \mathrm{~s}\left(\beta\right.$-actin); and extension at $72^{\circ} \mathrm{C}$ for $1 \mathrm{~min}$. The copy numbers of the transcripts were normalized against those of $\beta$-actin transcripts for each sample.

\section{Statistical analysis}

All data are presented as means \pm SD. Statistical analyses were performed using one-way and two-way analysis of variance (ANOVA) with Fisher's least significant difference, Student's $t$, Mann-Whitney's $U$, and Chi-square tests. Statistical significance was defined as $p<0.05$.

\section{Results}

\section{Body weight changes in pups during neonatal development}

There were no significant differences in body weights between the two maternal groups (i.e., $\mathrm{mNN}$ and $\mathrm{mUN}$ ) on day $15(321.1 \pm 23.1 \mathrm{~g}$ in $\mathrm{mNN} v s .316 .5 \pm 21.2 \mathrm{~g}$ in mUN) (Fig. 2). The body weights (\% of day 16) of the mUN group, in which dams received $50 \%$ of the daily food intake of the mNN group, was significantly lighter than that of $\mathrm{mNN}$ group from day 16 to day 21 (twoway ANOVA: $p<0.01$ on day 16 , and $p<0.001$ on day 21). Maternal food restriction during pregnancy had no effect on the total number of pups (Table 1). The number of dead pups at birth was not significantly different between the two groups (Chi-square test). The body weights of pups on postnatal day 1 in the mUN group were significantly lighter than those in the $\mathrm{mNN}$ group $(p<0.0001)$. Furthermore, the body weights of pups in the four postnatal nutrition groups were significantly different from postnatal day 4 to day 28 (control-HN $>$ IUGR-HN $>$ control-NN $>$ IUGR-NN, $p<0.05$ ) (Fig. $3)$. The body weights of pups on day 32 were signifi- cantly different in all groups, with the exception of the control-HN and IUGR-HN groups $(p<0.05)$. Pups in the IUGR-HN group demonstrated catch-up growth to the control-NN group, whereas pups in the IUGR-NN group did not demonstrate catch-up growth to the control-NN group during the study period.

Experiment 1. Body weight, ovarian and uterine weights, serum hormone levels, and mRNA expression of hypothalamic parameters on day 28

The offspring selected for Experiment 1 demonstrated similar differences in body weights as the entire offspring population (i.e., control-HN > IUGR-HN > control-NN $>$ IUGR-NN; $p<0.05$ ) (Table 2). Ovarian weights were not significantly different among the four groups, whereas uterine weights of the IUGR-NN group were significantly lighter than those of the other groups $(p<0.05)$. Serum LH $(p<0.05)$ and leptin $(p$ $<0.001)$ levels were significantly higher in the control-HN group than in any other group (Fig. 4). Serum FSH level, hypothalamic Kiss 1 and Kiss 1 r mRNA levels were not significantly different among all four groups. However, serum LH and leptin levels, as well as Kiss 1 and Kiss $1 r$ mRNA expression, tended to be lower in the IUGR-NN group than any other group. Furthermore, the parameters of the IUGR-HN group appeared to parallel those of the control-NN group than the IUGR-NN group.

\section{Experiment 2. Age of vaginal opening}

Three rats were excluded (i.e., one from control-NN, one from control-HN, and one from IUGR-NN), as they did not demonstrate $\mathrm{VO}$ until day 40. The cumulative rate of $\mathrm{VO}$ in the control groups was significantly higher than that of the IUGR groups from day 33 to day $37(p<0.05)$ (Fig. 5). The age of VO in the IUGR-NN group was $35.7 \pm 2.4$ days, which was significantly later than that of control-NN group (33.8 \pm 0.8 days). The age of $\mathrm{VO}$ in the IUGR-HN group was $35.6 \pm 2.3$ days, which was significantly later than that of the control-HN group (33.5 \pm 0.8 days; oneway ANOVA; $p<0.001$ ) (Table 3). Furthermore, the age of VO was not significantly different between the IUGR-NN and IUGR-HN groups, as well as the control-NN and control-HN groups. The body weights of the hypernutrition groups (i.e., control-HN and IUGR-HN) were significantly heavier than that of the normal nutrition groups (i.e., control-NN and IUGR-NN) on the day of VO $(p<0.001)$. 
Table 1 Influence of maternal nutrition on pregnancy

\begin{tabular}{|c|c|c|c|c|c|c|c|}
\hline & $\begin{array}{l}\text { Number of } \\
\text { pregnant } \\
\text { rats }\end{array}$ & $\begin{array}{l}\text { Number of } \\
\text { rats that } \\
\text { delivered }\end{array}$ & $\begin{array}{l}\text { Number of } \\
\text { rats aborted }\end{array}$ & $\begin{array}{c}\text { Total } \\
\text { number of } \\
\text { pups alive } \\
\text { at birth }\end{array}$ & $\begin{array}{c}\text { Total } \\
\text { number of } \\
\text { dead pups } \\
\text { at birth }\end{array}$ & Litter size & $\begin{array}{l}\text { Average } \\
\text { pups weight } \\
\text { on day } 1 \\
\text { (alive) }(\mathrm{g}) \\
\end{array}$ \\
\hline $\begin{array}{l}\text { Maternal } \\
\text { normal nutrition } \\
(\mathrm{mNN})\end{array}$ & 8 & 7 & 1 & 99 & 0 & $14.1 \pm 1.2$ & $6.4 \pm 0.5$ \\
\hline $\begin{array}{l}\text { Maternal } \\
\text { undernutrition } \\
\text { (mUN) }\end{array}$ & 9 & 9 & 0 & 129 & 2 & $14.3 \pm 2.0$ & $5.8 \pm 0.5 *$ \\
\hline
\end{tabular}

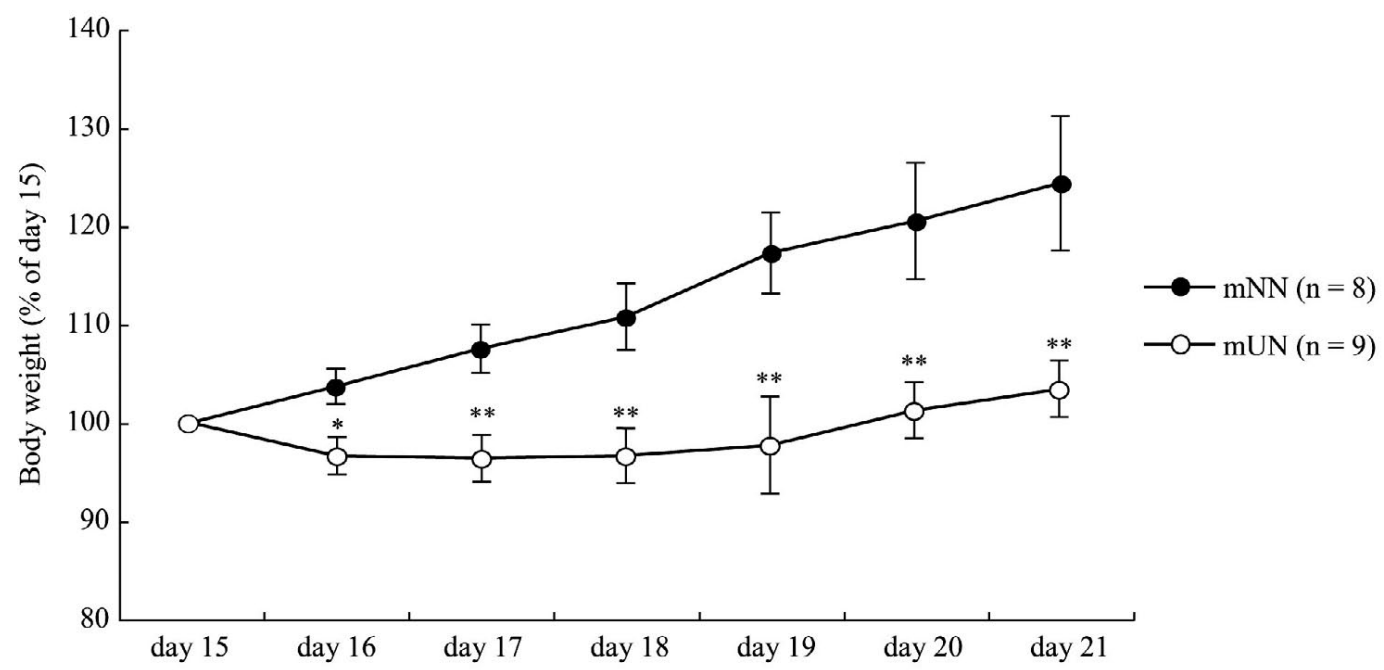

Fig. 2 Maternal body weight changes during pregnancy of the normal nutrition $(m N N, n=8)$ and undernutrition $(m U N, n=9)$ groups Undernutrition of rats during pregnancy (i.e., $50 \%$ of the daily food intake of the mNN group) resulted in reduced maternal weights during pregnancy. Body weights (\% of day 16) of the mUN group were significantly lighter those in the $\mathrm{mNN}$ group from day 16 to day 21 (two-way ANOVA; $p<0.01$ at day 16, and $p<0.001$ at day 21 ). ${ }^{*} p<0.01$ and $*^{*} p<0.001$.

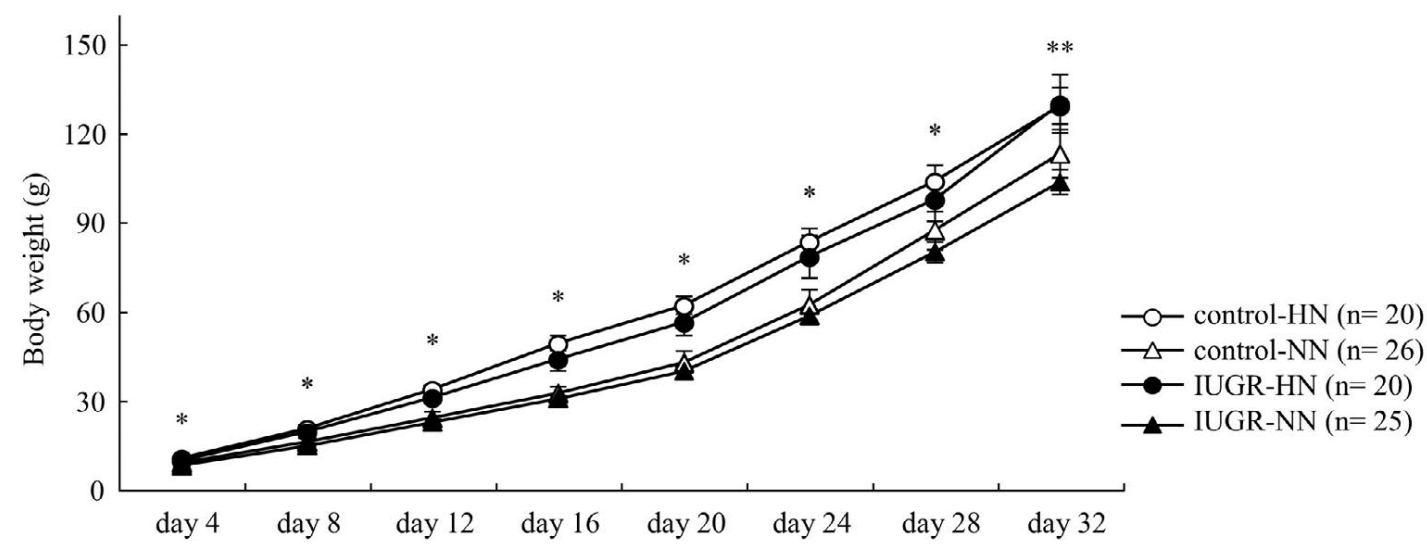

Fig. 3 Body weight changes during the neonatal development of the normal nutrition (control-NN, $n=26$; IUGR-NN, $n=25$ ) and hypernutrition (control-HN, $\mathrm{n}=20$; IUGR-HN, $\mathrm{n}=20$ ) offspring

Body weights of pups were significantly different in all four groups from postnatal day 4 to day 28. Eight pups were randomly selected from each group on day 28 for Experiment 1. Body weights on day 32 were significantly different in all four groups, with the exception of the hypernutrition groups. $* p<0.05$, all four groups; ${ }^{*} p<0.05$, control-NN $v s$. IUGR-NN 
Table 2 Body, ovarian, and uterine weights

\begin{tabular}{lcccc}
\hline & $\begin{array}{c}\text { Control-HN } \\
(\mathrm{n}=8)\end{array}$ & $\begin{array}{c}\text { Control-NN } \\
(\mathrm{n}=8)\end{array}$ & $\begin{array}{c}\text { IUGR-HN } \\
(\mathrm{n}=8)\end{array}$ & $\begin{array}{c}\text { IUGR-NN } \\
(\mathrm{n}=8)\end{array}$ \\
\hline Body weight $(\mathrm{g})$ & $102.1 \pm 4.2^{\mathrm{a}}$ & $85.8 \pm 5.4^{\mathrm{c}}$ & $96.2 \pm 5.7^{\mathrm{b}}$ & $80.3 \pm 2.6^{\mathrm{d}}$ \\
Ovarian weight (mg) & $36.5 \pm 5.9$ & $39.1 \pm 8.1$ & $37.3 \pm 6.0$ & $40.9 \pm 2.4$ \\
Uterine weight (mg) & $68.1 \pm 20.4$ & $64.6 \pm 13.8$ & $54.8 \pm 7.0$ & $50.4 \pm 6.5^{*}$ \\
\hline
\end{tabular}

$\mathrm{HN}$, hypernutrition; NN, normal nutrition

Different letters (a-d) show significant difference $(p<0.05)$ (mean $\pm \mathrm{SD})$.

$* p<0.05$, IUGR-NN $v s$. the other groups
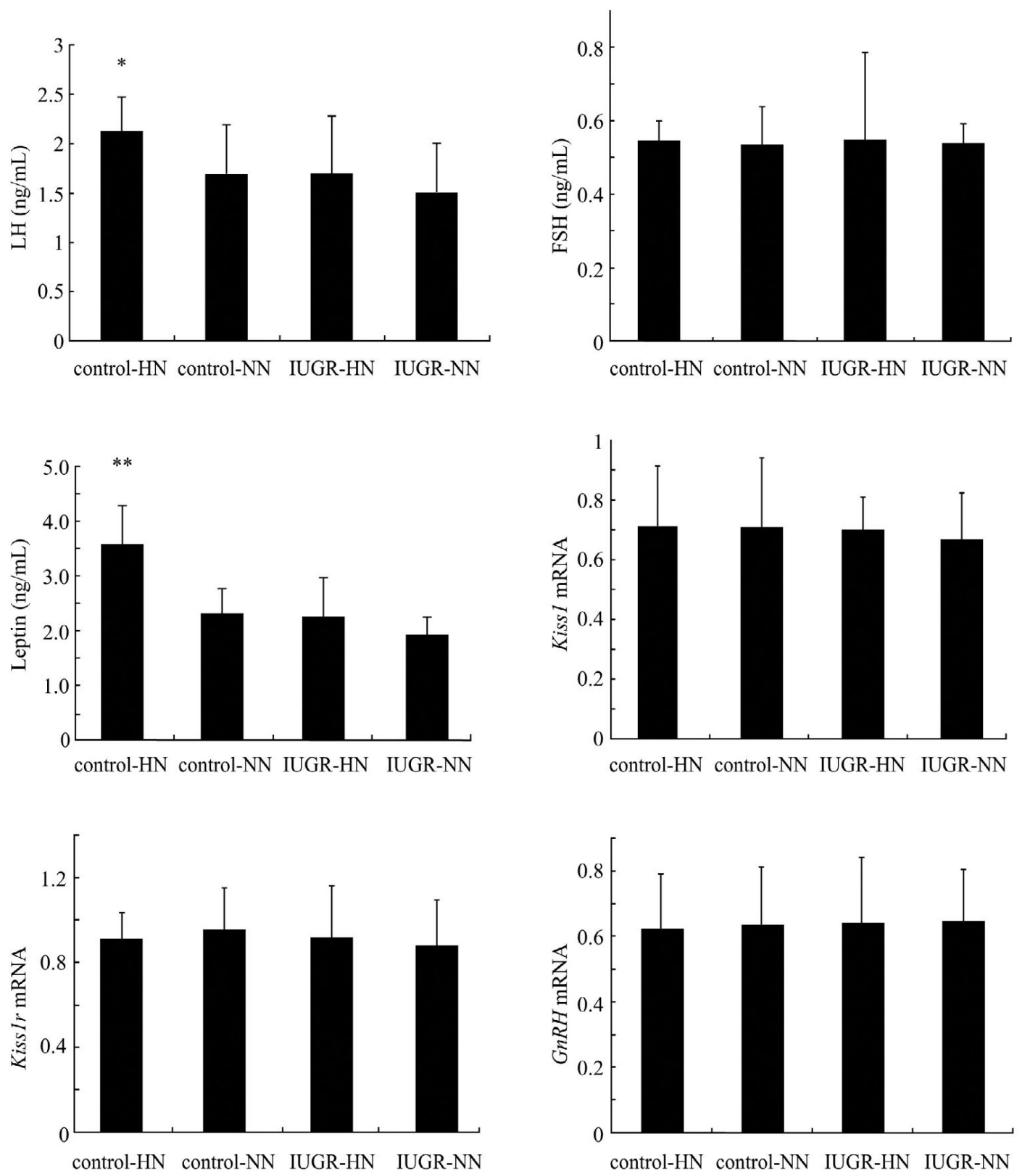

Fig. 4 Serum hormone and hypothalamic mRNA expression levels on postnatal day $28(\mathrm{n}=8$ per group)

Relative mRNA expression levels of Kiss 1, Kiss 1r, and GnRH were calculated by dividing by $\beta$-actin mRNA expression. $\mathrm{HN}$, hypernutrition; NN, normal nutrition Data are presented as mean $\pm \mathrm{SD} .{ }^{*} p<0.05,{ }^{* *} p<0.001$ 


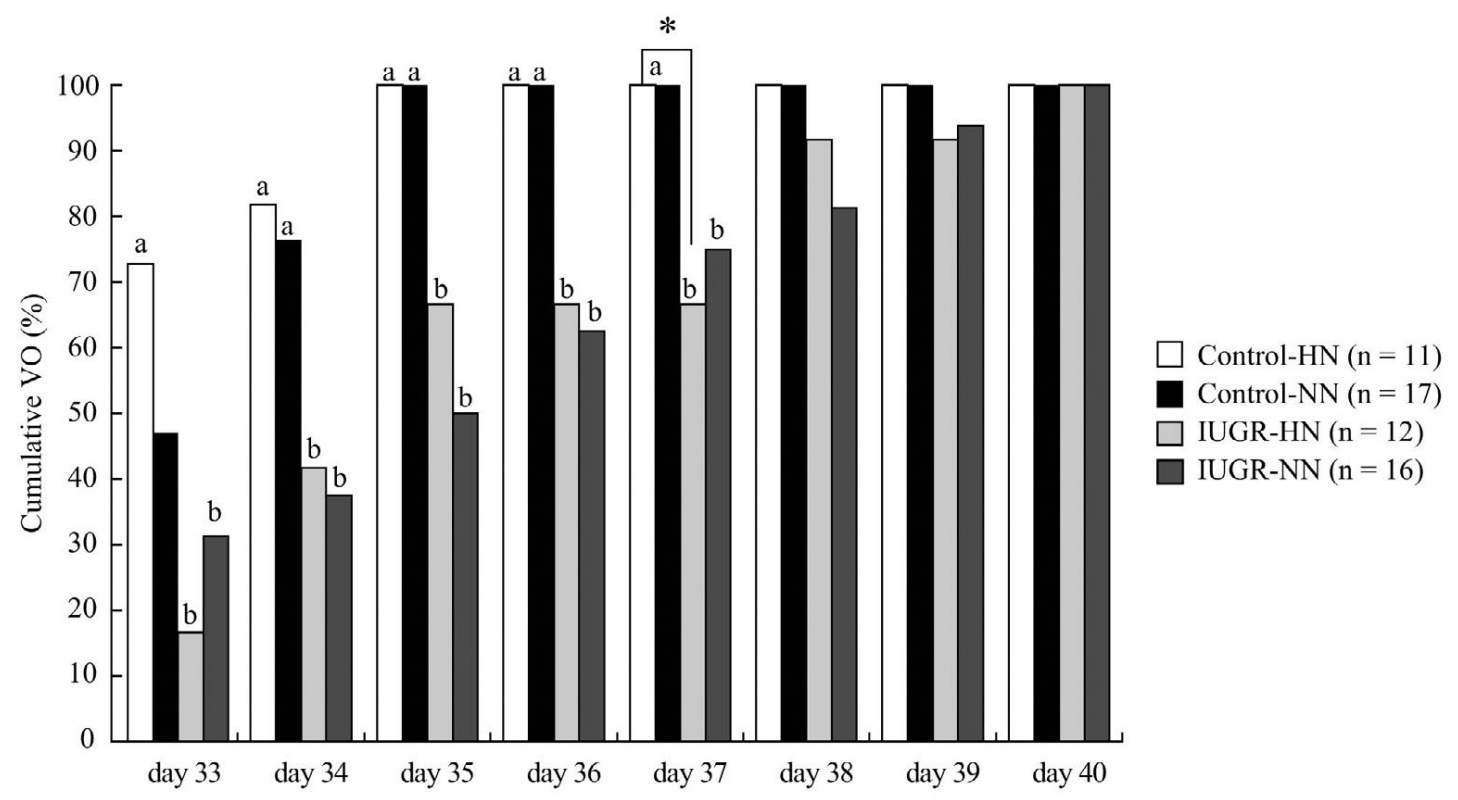

Fig. 5 Cumulative rate of vaginal opening $(\mathrm{VO})$ of normal nutrition (control-NN, $\mathrm{n}=17$; IUGR-NN, $\mathrm{n}=16$ ) and hypernutrition (control-HN, $\mathrm{n}=11$; IUGR-HN, $\mathrm{n}=12$ ) offspring

The cumulative rate of $\mathrm{VO}$ of the control groups was significantly higher than that of the IUGR groups from day 33 to day 37 . The age of VO was not significantly different between the IUGR-NN and IUGR-HN groups, as well as between the control-NN and controlHN groups. Different letters (a-b) show significant difference $(p<0.05) .{ }^{*} p<0.05$, control-HN vs. IUGR-HN

Table 3 Age of vaginal opening

\begin{tabular}{lcccc}
\hline & $\begin{array}{c}\text { Control-HN } \\
(\mathrm{n}=11)\end{array}$ & $\begin{array}{c}\text { Control-NN } \\
(\mathrm{n}=17)\end{array}$ & $\begin{array}{c}\text { IUGR-HN } \\
(\mathrm{n}=12)\end{array}$ & $\begin{array}{c}\text { IUGR-NN } \\
(\mathrm{n}=16)\end{array}$ \\
\hline Age of VO (day) & $33.5 \pm 0.8^{\mathrm{a}}$ & $33.8 \pm 0.8^{\mathrm{a}}$ & $35.6 \pm 2.3^{\mathrm{b}}$ & $35.7 \pm 2.4^{\mathrm{b}}$ \\
Body weight at VO $(\mathrm{g})$ & $136.2 \pm 6.9^{\mathrm{a}}$ & $117.0 \pm 9.8^{\mathrm{b}}$ & $141.1 \pm 15.6^{\mathrm{a}}$ & $112.5 \pm 7.7^{\mathrm{b}}$ \\
\hline
\end{tabular}

Different letters $(\mathrm{a}-\mathrm{b})$ show significant difference $(p<0.05)($ mean $\pm \mathrm{SD})$.

\section{Discussion}

It is well known that perinatal undernutrition disturbs the development of reproductive function. In the present study, we demonstrated that maternal undernutrition induces a delay in the onset of puberty in female offspring, and that this delay in the onset of puberty cannot be rescued with postnatal hypernutrition. Maternal undernutrition resulted in reduced maternal weights during pregnancy, as well as offspring body weights at birth. Postnatal hypernutrition significantly enhanced offspring growth in comparison to offspring exposed to normal postnatal nutritional conditions, regardless of their prenatal nutritional conditions. Furthermore, the ages of $\mathrm{VO}$ were delayed in the prenatal undernutrition groups, regardless of their postnatal nutritional conditions. The age of VO was not clearly correlate with serum levels of LH and leptin, or mRNA expressions of Kiss 1 and Kiss $1 r$. In fact, these parameters were similar in the IUGR-HN and control-NN groups. These similarities may be due to the catch-up growth of the IUGR-HN offspring to the control-NN offspring. However, the increases in leptin levels, which stimulate hypothalamic Kiss 1 mRNA expression, did not rescue the delay of VO in IUGR-HN offspring.

It has been shown that IUGR rats that demonstrated rapid catch up growth in the early developmental period showed hypothalamic leptin resistance and increased body weight and body fat [34] and leptin resistance induces hypothalamic infertility, which is caused by the suppression of GnRH mRNA expression [36]. It has been shown that Kiss 1 mRNA expression is regulated by leptin, and that the decreased action of leptin suppresses Kiss1 mRNA expression in the 
hypothalamus $[31,37]$. We previously reported that prenatal undernutrition-induced IUGR rats demonstrate rapid catch-up growth in the early developmental period, and have increased leptin resistance in the hypothalamic kisspeptin system, which may lead to decreases in Kiss 1 mRNA expression and delays in VO [35]. In the present study, we assessed the effects of postnatal hypernutrition on prenatal undernutrition-induced IUGR rats. IUGR-NN rats did not demonstrate a similar catch-up growth phase found in our previous study [35] and the leptin resistance in the kisspeptin systems was not seen in this study. This discrepancy in offspring growth may be due to potential differences in experimental conditions. Interestingly, despite the fact that IUGR rats did not undergo catch-up growth and showed adequate serum leptin levels and Kiss1 mRNA expressions, they still demonstrated a delay in VO. Taken together, these findings suggest that prenatal undernutrition-induced IUGR rats demonstrate delayed VO, regardless of their postnatal nutritional conditions and/or achievement of catch-up growth.

Prenatal undernutrition may alter endocrine programming relating to the onset of puberty. Additionally, ovarian function appears to be disturbed in low birth weight or IUGR animal models and humans. Prenatal undernutrition-induced IUGR rats have a smaller number of primordial, growing and antral follicles in their ovaries [38]. In a pig model, the number of primary follicles was reduced and secondary follicles were absent in the ovaries of IUGR runts [39]. Thus, prenatal undernutrition appears to disturb ovarian function, and may be a contributing factor in the delay of VO in IUGR pups. Additionally, postnatal nutrition (i.e., maternal protein- and energy-restricted diets during lactation) has been shown to also reduce the number of primordial follicles, Graafian follicles and the corpus luteum, as well as the number of ovarian estrogen and androgen receptors in rat offspring [40]. Furthermore, these ovaries demonstrate a decrease in the mRNA expression of the follicle-stimulating hormone (FSH) receptor, LHR, aromatase, leptin and leptin receptor [41]. Although postnatal undernutrition appears to interfere with ovarian function, postnatal hypernutrition does not appear to induce any beneficial effects on ovarian function over normal postnatal nutrition. In the present study, despite that control-HN offspring were heavier than control-NN offspring, the age of VO was similar.

A number of studies demonstrated that the onset of puberty or menarche was 4-18 months earlier in girls born small for gestational age (SGA) than those appropriate for gestational age (AGA) in Sweden, India, Spain and Italy [42-45]. Additionally, adolescent girls born SGA demonstrated a lower ovulation rate [46], reduced uterine and ovarian size, and ovarian hyporesponsiveness to FSH $[47,48]$. In IUGR fetuses, ovarian development, as well as the development of other organs, was impaired, and these fetuses also had a significantly lower percentage of primordial follicles in their ovaries compared to matched controls [14]. Studies on humans have found that girls who experienced prenatal undernutrition had an earlier onset of puberty. These findings are contrary to those of animal studies, in which female pups that experienced prenatal undernutrition demonstrated a delay in the onset of puberty. Regardless, these findings suggest that prenatal undernutrition or fetal growth retardation disturbs ovarian development, and thereby may increase the risk of fertility problems later in adult life for females.

In conclusion, maternal undernutrition induces a delay in puberty in female rat offspring that cannot be rescued by hypernutrition after the birth. Thus, adequate maternal nutrition during pregnancy appears to be extremely important for the health of offspring, not only for proper metabolic function, but also for reproductive function.

\section{References}

1. Lucas A (1990) Does early diet program future outcome? Acta Paediatr Scand Suppl 365: 58-67.

2. Godfrey KM, Barker DJ (2000) Fetal nutrition and adult disease. Am J Clin Nutr 71: 1344S-1352S.

3. Breier BH, Vickers MH, Ikenasio BA, Chan KY, Wong WPS (2001) Fetal programming of appetite and obesity. Mol Cell Endocrinol 185: 73-79.

4. Barker DJ (1995) Intrauterine programming of adult disease. Mol Med Today 1: 418-423.

5. Hattersley AT, Tooke JE (1999) The fetal insulin hypothesis: an alternative explanation of the association of low birth weight with diabetes and vascular disease. Lancet 353: 1789-1792.

6. Engelbregt MJ, Houdijk ME, Popp-Snijders C, Delemarre-van de Waal HA (2000) The effects of intrauterine growth retardation and postnatal undernutrition 
on onset of puberty in male and female rats. Pediatr Res 48: 803-807.

7. Leonhardt M, Lesage J, Croix D, Dutriez-Casteloot I, Beauvillain JC, Dupouy JP (2003) The effects of perinatal maternal food restriction on pituitary-gonadal axis and plasma leptin level in rat pup at birth and weaning and on timing of puberty. Biol Reprod 68: 390-400.

8. Guzman C, Cabrera R, Cardenas M, Larrea F, Nathanielsz PW, Zambrano E (2006) Protein restriction during fetal and neonatal development in the rat alters reproductive function and accelerates reproductive ageing in female progeny. $J$ Physiol 572: 97-108.

9. Smith JT, Waddell BJ (2000) Increased fetal glucocorticoid exposure delays puberty onset in postnatal life. Endocrinology 141: 2422-2428.

10. Rae MT, Kyle CE, Miller DW, Hammond AJ, Brooks AN, Rhind SM (2002) The effects of undernutrition, in utero, on reproductive function in adult male and female sheep. Anim Reprod Sci 72: 63-71.

11. Edwards CR, Benediktsson R, Lindsay RS, Seckl JR (1993) Dysfunction of the placental glucocorticoid barrier: a link between the fetal environment and adult hypertension? Lancet 341: 355-357.

12. Phillips DI (1998) Birth weight and the future development of diabetes. Diabetes Care 21 Suppl 2: B150B155.

13. Lesage J, Blondeau B, Grino M, Breant B, Dupouy JP (2001) Maternal undernutrition during late gestation induces fetal overexposure to glucocorticoids and intrauterine growth retardation, and disturbs the hypothalamo-pituitary adrenal axis in the newborn rat. Endocrinology 142: 1692-1702.

14. de Bruin JP, Dorland M, Bruinse HW, Spliet W, Nikkels PG, Te Velde ER (1998) Fetal growth retardation as a cause of impaired ovarian development. Early Hum Dev 51: 39-46.

15. Ibanez L, De Zegher F, Potau N (1999) Anovulation after precocious pubarche: early markers and time course in adolescence. J Clin Endocrinol Metab 84: 2691-2695.

16. Bieswal F, Ahn MT, Reusens B, Holvoet P, Raes M, Rees WD, Remacle C (2006) The importance of catch-up growth after early malnutrition for the programming of obesity in male rat. Obesity 14: 1330-1343.

17. Kaplowitz PB (2008) Link between body fat and the timing of puberty. Pediatrics 121: S208-217.

18. Biro FM, Khoury P, Morrison JA (2006) Influence of obesity on timing of puberty. Int J Androl 29: 272-277.

19. Jasik CB, Lustig RH (2008) Adolescent obesity and puberty: the "perfect storm." Ann N Y Acad Sci 1135: 265-279.

20. Ahima RS, Dushay J, Flier SN, Prabakaran D, Flier JS (1997) Leptin accelerates the onset of puberty in normal female mice. J Clin Invest 99: 391-395.

21. Cheung CC, Thornton JE, Kuijper JL, Weigle DS, Clifton DK, Steiner RA (1997) Leptin is a metabolic gate for the onset of puberty in the female rat. Endocrinology 138: 855-858.

22. Cunningham MJ, Clifton DK, Steiner RA (1999) Leptin's actions on the reproductive axis: perspectives and mechanisms. Biol Reprod 60: 216-222.

23. Zeinoaldini S, Swarts JJ, van de Heijning BJ (2006) Chronic leptin infusion advances, and immunoneutralization of leptin postpones puberty onset in normally fed and feed restricted female rats. Peptides 27: 16521658.

24. Hassink SG, Sheslow DV, de Lancey E, Opentanova I, Considine RV, Caro JF (1996) Serum leptin in children with obesity: relationship to gender and development. Pediatrics 98 (2Pt1): 201-3.

25. Shaltin S, Phillip M (2003) Role of obesity and leptin in the pubertal process and pubertal growth. Int J Obes Relat Metab Disord 27: 869-874.

26. de Roux N, Genin E, Carel JC, Matsuda F, Chaussain JL, Milgrom E (2003) Hypogonadotropic hypogonadism due to loss of function of the KiSS1-derived peptide receptor GPR54. Proc Natl Acad Sci USA 100: 1097210976.

27. Seminara SB, Messager S, Chatzidaki EE, Thresher RR, Acierno JS Jr, Shagoury JK, Bo-Abbas Y, Kuohung W, Schwinof KM, Hendrick AG, Zahn D, Dixon J, Kaiser UB, Slaugenhaupt SA, Gusella JF, O'Rahilly S, Carlton MB, Crowley WF, Aparicio SA, Colledge WH (2003) The GPR54 gene as a regulator of puberty. $N$ Engl $J$ Med 349: 1614-1627.

28. Irwig MS, Fraley GS, Smith JT, Acohido BV, Popa SM, Cunningham MJ, Gottsch ML, Clifton DK, Steiner RA (2004) Kisspeptin activation of gonadotropin releasing hormone neurons and regulation of KiSS-1 mRNA in the male rat. Neuroendocrinology 80: 264-272.

29. Matsui H, Takatsu Y, Kumano S, Matsumoto H, Ohtaki $\mathrm{T}$ (2004) Peripheral administration of metastin induces marked gonadotropin release and ovulation in the rat. Biochem Biophys Res Commun 320: 383-388.

30. Castellano JM, Bentsen AH, Sanchez-Garrido MA, Ruiz-Pino F, Romero M, Garcia-Galino D, Aguilar E, Pinilla L, Dieguez C, Mikkelsen JD, Tena-Sempere M (2011) Early metabolic programming of puberty onset: impact of changes in postnatal feeding and rearing conditions on the timing of puberty and development of the hypothalamic kisspeptin system. Endocrinology 152(9): 3396-3408.

31. Smith JT, Acohido BV, Clifton DK, Steiner RA (2006) KiSS-1 neurones are direct targets for leptin in the ob/ ob mouse. J Neuroendocrinol 18: 298-303.

32. Castellano JM, Navarro VM, Fernandez-Fernandez R, Roa J, Vigo E, Pineda R, Dieguez C, Aguilar E, Pinilla L, Tena-Sempere M (2006) Expression of hypothalamic KiSS-1 system and rescue of defective gonadotropic responses by kisspeptin in streptozotocin-induced diabetic male rats. Diabetes 55: 2602-2610. 
33. Iwasa T, Matsuzaki T, Murakami M, Shimizu F, Kuwahara A, Yasui T, Irahara M (2008) Decreased expression of kisspeptin mediates acute immune/ inflammatory stress-induced suppression of gonadotropin secretion in female rat. $J$ Endocrinol Invest 31: 656659.

34. Desai M, Gayle D, Babu J, Ross MG (2005) Programmed obesity in intrauterine growth-restricted newborns: modulation by newborn nutrition. Am J Physiol Regul Integr Comp Physiol 288: R91-R96.

35. Iwasa T, Matsuzaki T, Murakami M, Fujisawa S, Kinouchi R, Gereltsetseg G, Kuwahara A, Yasui T, Irahara M (2010) Effects of intrauterine undernutrition on hypothalamic Kiss1 expression and the timing of puberty in female rats. $J$ Physiol 588(5): 821-829.

36. Tortoriello DV, McMinn J, Chua SC (2004) Dietaryinduced obesity and hypothalamic infertility in female DBA/2J mice. Endocrinology 145: 1238-1247.

37. Castellano J, Roa J, Luque RM, Dieguez C, Aguilar E, Pinilla E, Tena-Sempere M (2009) KiSS-1/kisspeptins and the metabolic control of reproduction: physiologic roles and putative physiopathological implocations. Peptides 30: 139-145.

38. Engelbregt MJ, van Weissenbruch MM, Popp-Snijders C, Delemarre-van de Waal HA (2002) Delayed first cycle in intrauterine growth-retarded and postnatally undernourished female rats: follicular growth and ovulation after stimulatin with pregnant mare gonadotropin at first cycle. J Endocrinol 173: 297-304.

39. da Silva-Buttkus P, van den Hurk R, te Velde ER, Taverne MA (2003) Ovarian development in intrauterine growth-retarded and normally developed piglets originating from the same litter. Reproduction 126: 249258.

40. da Silva Faria T, de Bittencourt Brasil F, Sampaio FJ, da Fonte Ramos C (2010) Effects of maternal undernutrition during lactation on estrogen and androgen receptor expressions in rat ovary at puberty. Nutrition 26: 993999.

41. da Silva Faria T, de Bittencourt Brasil F, Sampaio FJ, da Fonte Ramos C (2010) Maternal malnutrition during lactation affects folliculogenesis, gonadotropins, and leptin receptors in adult rats. Nutrition 26: 1000-1007.

42. Persson I, Ahlsson F, Ewald U, Tuvemo T, Qingyuan M, von Rosen D, Proos L (1999) Influence of perinatal factors on the onset of puberty in boys and girls: implications for interpretation of link with risk of long term diseases. Am J Epidem 150: 747-755.

43. Bhargava SK, Ramji S, Srivastava U, Sachdev HP, Kapani V, Datta V, Satyanarayana L (1995) Growth and sexual maturation of low birthweight children: a 14 year follow-up, Indian Pediatr 32: 963-970.

44. Ibanez L, Ferrer A, Marcos MV, Hierro FR, de Zegher F (2000) Early puberty: rapid progression and reduced final height in girls with low birth weight. Pediatrics 106 (5): E72.

45. Ghirri P, Bernardini M, Vuerich M, Cuttano AM, Coccoli L, Merusi I, Ciulli C, DíAccavio L, Bottone U, Boldrini A (2001) Adrenarche, pubertal development, age at menarche and final height of full-term, born small for gestational age (SGA) girls. Gynecol Endocrinol 15: 91-97.

46. Ibanez L, Potau N, Ferrer A, Rodriguez-Hierro F, Marcos MV, de Zegher F (2002) Reduced ovulation rate in adolescent girls born small for gestational age. J Clin Endocrinol Metab 87: 3391-3393.

47. Ibanez L, Potau N, Enriquez G, de Zegher F (2000) Reduced uterine and ovarian size in adolescent girls born small for gestational age. Pediatr Res 47: 575577.

48. Ibanez L, Potau N, de Zegher F (2000) Ovarian hyporesponsiveness to follicle stimulating hormone in adolescent girls born for gestational age. J Clin Endocrinol Metab 85: 2624-2626. 